\title{
Active Condition Monitoring of a Marine Gas Turbine through Rotor Shaft Vibration Analysis
}

\author{
Ogbonnaya EA ${ }^{1, *}$, Ugwu HU ${ }^{2}$, Poku R ${ }^{1}$, Adigio EM ${ }^{1}$ \\ ${ }^{1}$ Department of Mechanical/Marine Engineering, Niger Delta University, Wilberforce Island, Yenagoa, Bayelsa State, Nigeria \\ ${ }^{2}$ Department of Mechanical Engineering, Michael Okpara University of Agriculture, Umudike, Umuahia, Abia State, Nigeria \\ *Corresponding author: ezenwaogbonnaya@yahoo.com
}

Received March 20, 2013; Revised May 09, 2013; Accepted May 25, 2013

\begin{abstract}
While preventive and predictive maintenance have played their part in engine health monitoring, the problem of downtime maintenance has truly reached a serious level. Also, most companies have found out that their maintenance costs can be cut drastically by establishing a proactive line of defence. Most imminent faults in gas turbines often result from the vibration of the rotor shaft of the engine. Some of these faults that could lead to catastrophy include misalignment, imbalance, cracks and eccentricity. These defects are equally likely to lead to unscheduled downtime resulting to large economic losses. It is on this backdrop that the rotor shaft of a marine gas turbine system was isolated and used for condition monitoring to enunciate methods to reduce downtime. The need to study vibration which is one of the biggest threats to rotating equipment has become much required now than ever before. This project thus presents a case to monitor the condition of the gas turbine through its thermodynamic and rotor shaft vibration analyses. Selected measurements from an industrial gas turbine to detect changes in operating conditions of the plant were of immense help in setting the proactive measures for the plant. Simulation and analysis were achieved using high level java computer programming language and data collected from a gas turbine plant. The work shows that vibration reduces the active load of the engine. Thus, proactive maintenance monitoring programs should be employed in gas turbine usage to avoid the effects of vibration.
\end{abstract}

Keywords: gas turbine, rotor shaft, vibration, maintenance, active condition monitoring

\section{Introduction}

Previously, maintenance was conducted only when equipment actually failed (Ogbonnaya 2004a). The work was more "fix it" than maintenance. Thereafter, the recognition that performing regular maintenance and refurbishment tasks on equipment could keep them operating longer between failures (Rao, 2001) came up. Plainly stated, the growing cost of maintenance is a serious business. According to Dodd (2000) and Chaplin (2006), "maintenance is the largest single controllable expenditure in a plant: in many companies it often exceeds annual net profit." One major U.S. automotive manufacturer has a maintenance staff of between 15,000 and 18,000 , all plants combined. They say " 85 to $90 \%$ is crisis work" (breakdown).

Preventive maintenance, when well implemented, has been shown to produce savings in excess of $25 \%$. Beyond that, its benefit quickly approaches a point of diminishing return (Tarbet, 2001). According to a Forbes Magazine study, one out of every three dollars spent on preventive maintenance is wasted. A major overhaul facility reports that "60 percent of hydraulic pumps sent in for rebuild had nothing wrong with them". These inefficiencies are the result of maintenance performed in accordance with unscheduled (guess work) as opposed to the machine's true condition and need (Denton and Ritmiller, 2001).
Most recently, predictive maintenance (also known as condition monitoring) has been leading the way to additional savings over preventive maintenance. The use of real time or portable instruments such as vibration monitors, thermography, ferrography, etc. have been effective at recognizing the symptoms of impending machine failure. The major benefit is the availability of an early warning, from a few hours to a few days, which reduces the number of breakdown and "catastrophic" failures (Bertele, 2002).

Predictive maintenance is usually implemented concurrently with preventive maintenance. Its targets are both the warning signs of impending failure and the recognition of small failures that begin the chain reaction which leads to catastrophic failures i.e., damage control (Bertele, 2002).

Conversely, proactive maintenance has now received worldwide recognition as the single most important means of achieving unsurpassed savings by conventional maintenance techniques. The approach supplants the maintenance philosophy of "failure reactive" with "failure proactive" by avoiding the underlying conditions that lead to machine faults and degradation. Unlike predictive/preventive maintenance, proactive maintenance commissions corrective actions aimed at failure root causes, not just symptoms. (Verdegan, 2002).

The cost-saving trend is toward a maintenance program that targets the root causes of machine wear and failure. Predictive and preventive methods are out: proactive 
maintenance is in. Why? Proactive maintenance methods are currently saving industries of all sizes thousands, even millions of dollars on machine maintenance every year. This paper therefore looked at how an active and systematic procedure could further be adopted to save the Marine Gas Turbine (MGT) engine from catastrophic failure through vibration analysis.

\section{Materials and Methods}

The engine used for this work is a marinalized aeroderived 75 MW plant called Afam III, GT 17, Type 13D manufactured by ABB ( ALSTOM) on industrial duty for electricity generation. It is located in Afam, near Port Harcourt, Rivers State, South-South, Nigeria. To present this analytic model of the (MGT), proactive condition monitoring through rotor shaft vibration analysis, a high level java computer program was used to perform the simulation. Selected measurements from the industrial GT to detect changes in operating conditions of the plant was of immense help in setting proactive measurements for the plant. To do this, a number of GT formulae were used.

\subsection{Gas Turbine Plant}

According to Ogbonnaya (2004b), Gas Turbines (GTs) usually operate on an open cycle, with four basic processes as shown in Figure 1, Figure 2 and Figure 3.The following equations were used.

$$
\begin{gathered}
\text { Compressor work }=h_{2}-h_{1}=c_{p}\left(T_{2}-T_{1}\right) \\
\text { Turbine work }=h_{3}-h_{4}=c_{p}\left(T_{3}-T_{4}\right) \\
\text { Heat supplied }=h_{3}-h_{2}=c_{p}\left(T_{3}-T_{2}\right) \\
\text { Heat rejected }=h_{4}-h_{1}=c_{p}\left(T_{4}-T_{1}\right)
\end{gathered}
$$

Thermal efficiency $(\eta)=\frac{\text { Net work transfered }}{\text { Heat energy supplied }}$

$$
\begin{aligned}
& =\frac{\text { work of Turbine of compressor }}{\text { Heat energy supplied }} \\
\eta & =1-\frac{T_{4}-T_{1}}{T_{3}-T_{2}}
\end{aligned}
$$

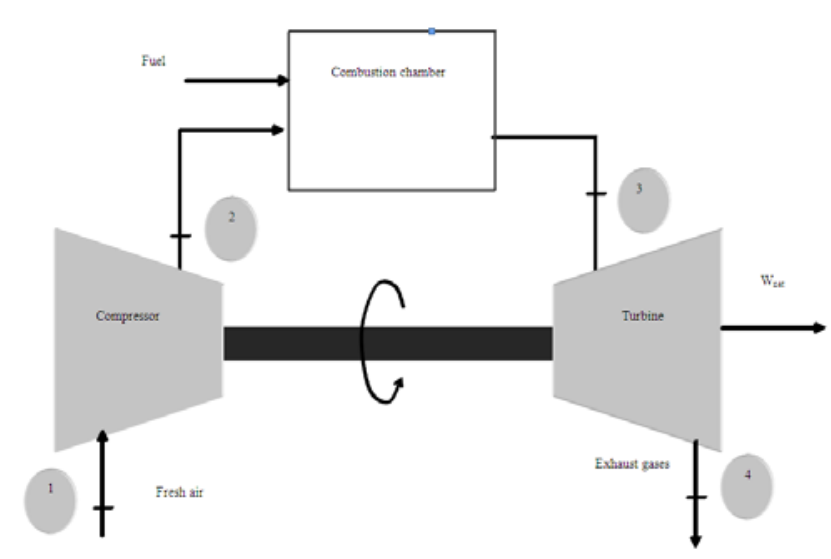

Figure 1. Open cycle GT engine (Ogbonnaya 2004b)

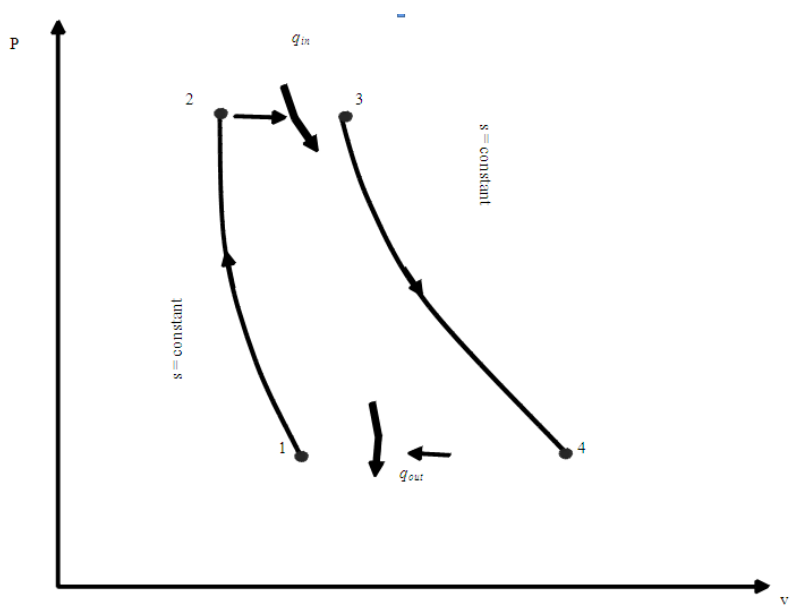

Figure 2. P-V diagram of Brayton Cycle (Ogbonnaya, 2004b)

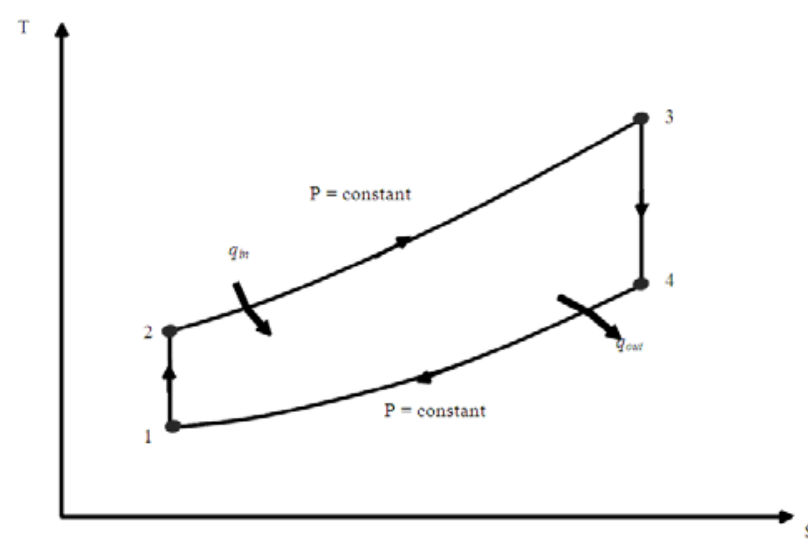

Figure 3. T-S diagram of Brayton Cycle (Ogbonnaya, 2004b) thus;

$$
\frac{T_{2}}{T_{1}}=\left(\frac{P_{2}}{P_{1}}\right)^{\frac{(r-1)}{\gamma}} \text { and } \frac{T_{3}}{T_{4}}=\left(\frac{P_{3}}{P_{4}}\right)^{\frac{(r-1)}{\gamma}}
$$

But $\frac{P_{2}}{P_{1}}=r_{P}$, thus,

$$
T_{2}=T_{1} r_{P}^{\frac{(r-1)}{\gamma}} \text { and } T_{3}=T_{4} r_{P}^{\frac{(r-1)}{\gamma}}
$$

Substituting into equation (6) and simplifying gives,

$$
\eta=1-\frac{1}{r_{p}\left(\frac{r-1}{r}\right)}
$$

where $r_{p}$ is the pressure ratio and $\square$ is the specific heat ratio (Çengel and Boles, 1998).

\subsection{Vibration of Rotor Shafts}

Vibration could be rectilinear or torsional. Torsional vibration is of more consequence to a rotating system. It is a kind of periodic angular motion of elastic shafts with circular rotors rigidly attached to them. This type of vibration is peculiar to GT rotors. The compressors and the turbines of the GT plant are periodically affected by the action of vibration (Maynard et al, 2001). In this work, consideration was given to a spring-mass system constrained to move in the vertical direction and excited 
by a rotating machine that is unbalanced, as shown in Figure 4. The unbalance is represented by an eccentric mass, $m$ with changing eccentricity, $e$, which is rotating with angular velocity, $\omega$. By letting $x$ be the displacement of the non-rotating mass $(M-m)$ from the static equilibrium position, the displacement of $m$ is:

$$
x=\dot{x}+e \sin \omega t
$$

Thus the equation of motion then becomes

$$
\ddot{m} x+c \dot{x}+k x=m e \omega^{2} \sin \omega t
$$

The vibration displacement amplitude is

$$
X=\frac{m e \omega^{2}}{\sqrt{\left(k-m e \omega^{2}\right)^{2}+(c \omega)^{2}}}
$$

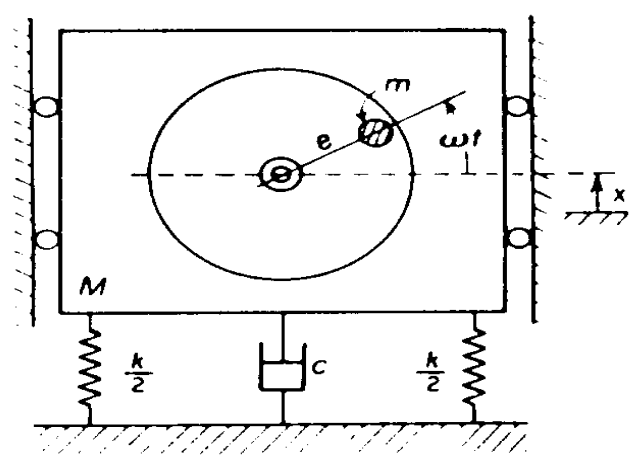

Figure 4. Harmonic disturbing force resulting from rotating unbalance (Source: Katsuhiko, 2005)

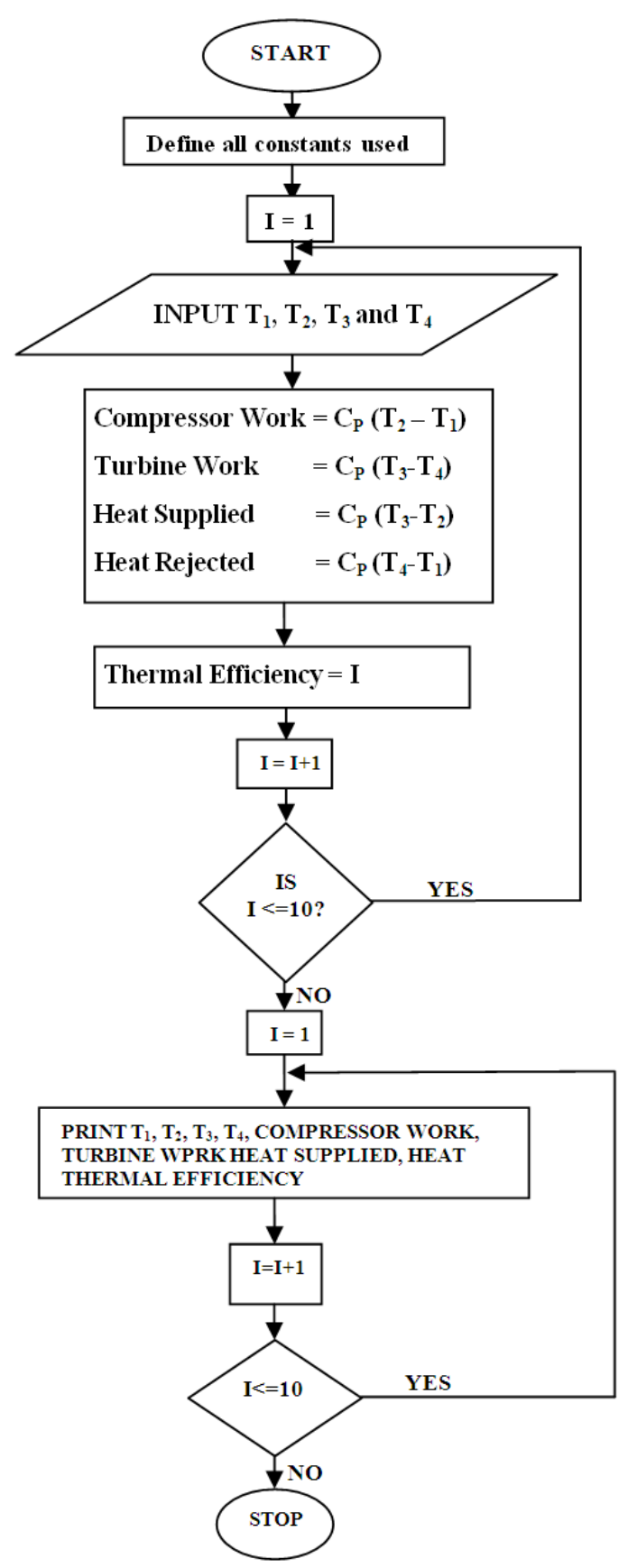

Figure 5. Flowchart to compute GT thermodynamics analysis using temperatures 


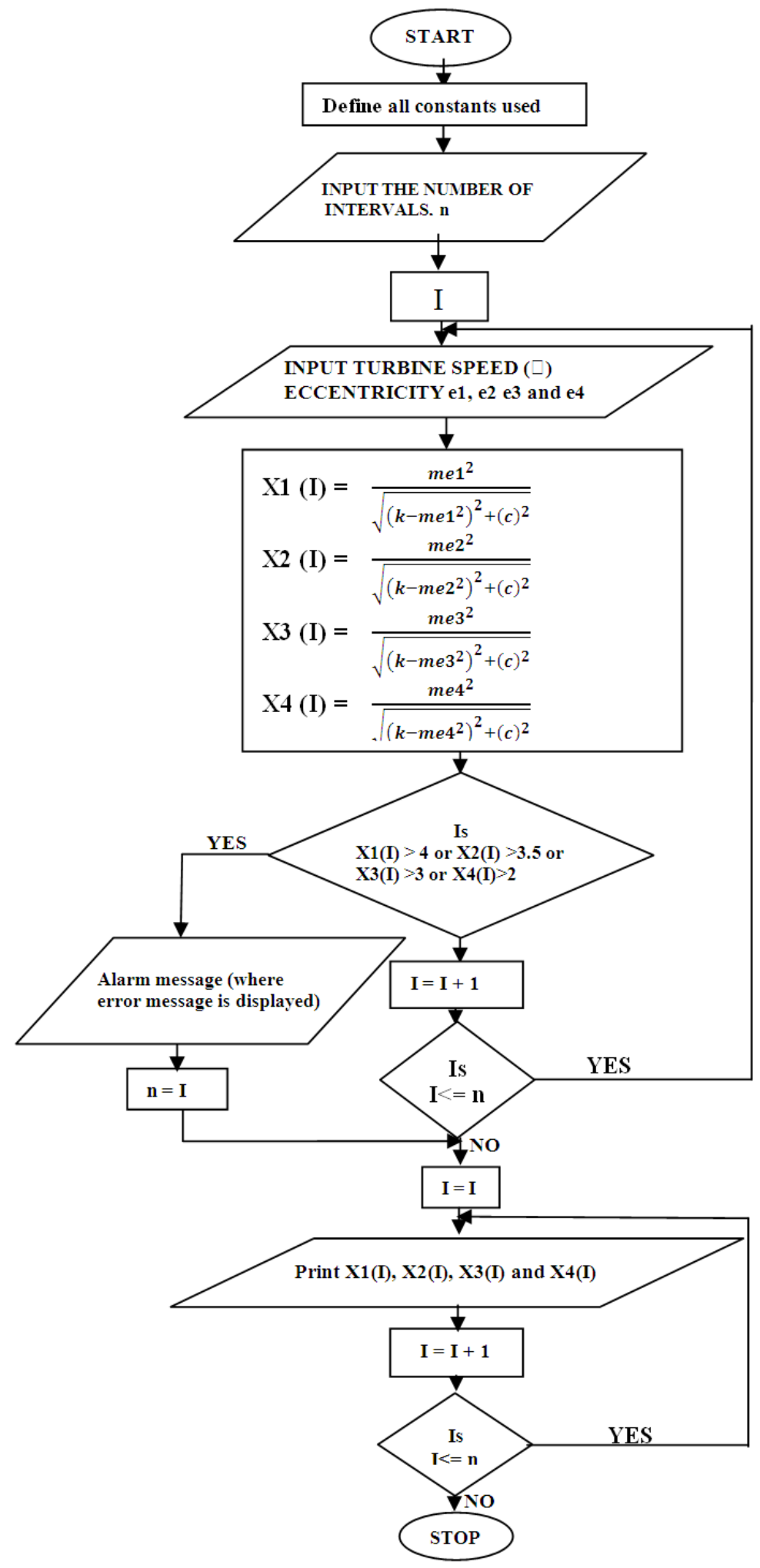

Figure 6. Flowchart for computing vibration displacement amplitude on bearings 1-4

Two flowcharts shown in Figure 5 and Figure 6 were drawn from equations 5 and 10 to represent the respective contributions of the thermodynamic and vibration analyses to the active/ dynamic condition monitoring of the GT system. The double-loop flowchart in Figure 5 helped to compute the operating temperatures in the system in order to maintain the required thermal efficiency. The multiloop flowchart in Figure 6 helps to keep a check on the vibration displacement amplitude of the various bearings to make sure that set and safe operational values are not exceeded during the running of the engine. These are the vibration levels that, if they are exceeded, the program should stop the engine. The java program from this flowchart also ascertains that alarm messages are generated/ displayed if the plant should be distressed and suddenly stopped.

\section{Results and Discussion}

Various graphs were plotted to provide for proactive condition monitoring of GTs through thermodynamics and 
rotor shafts vibration analysis. Different computer models were also developed for the analysis. The GT thermodynamic analysis obtained from the compressor, combustor and turbine temperature and pressure values shown in Appendix A were first analysed to determine the efficiency of the GT holistically.

Frequency and amplitude calculations were also computed using turbine speed, eccentricity and active load of the engine. The GT thermodynamic simulation models are shown in Figure 5 and Figure 6. They were used to generate the compressor work, turbine work, combustor heat supplied, network done and the efficiency necessary to determine the capacity of the turbine plant.

\subsection{Vibration Analysis}

The vibration analysis conducted was done by employing different computer models. The first model was developed for calculating the critical torsional frequency. With the assumption of the value of $\omega$, the process was initiated by assuming unit amplitudes of vibration for the first or free mass. Based on this, the amplitude and inertia force of the remaining masses were then calculated. The oscillating frequency at varying load was obtained using the rotating speed of the turbine. It was not allowed to exceed or equal the natural frequency above to avoid system resonance.

The second computer model was used to calculate the natural frequency, damping ratio, maximum amplitude at steady state for the unbalance. Both models are shown in Figure 7 and Figure 8 respectively. The generated result is shown in Appendix B.

By inputting the turbine speed for the engine and the various eccentricities relative to the bearing position from the reference point, the corresponding active load, frequencies and vibration displacement amplitudes on the respective bearings were generated. The data in Appendix $B$ were used to plot different graphs. The vibration amplitude on the four bearings was plotted against the turbine speed. The graph is shown in Figure 9, and it was observed that the vibration amplitudes at different bearings were almost constant while the speed of the turbine increased. These high vibration amplitudes at the bearing housings are danger signs that should be monitored in proactive condition monitoring as they can be responsible for the failure of GT shafts causing misalignment and other fatal accidents.

A graph of the active load against turbine speed was also plotted as shown in Figure 10. In a normal situation, a plot of active load against turbine speed should or is expected to produce a seemingly linear graph, but as was observed, there were fluctuations along the line. This shows that the engine load fluctuates with speed due to vibration. It is also clear that vibration reduces the active load, thus reducing useful energy.

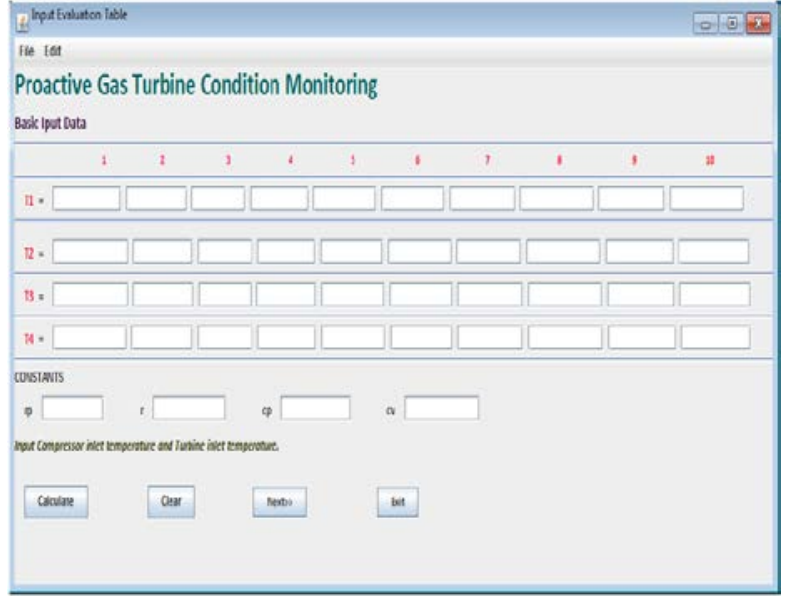

Figure 7. Input evaluation interface for computer model

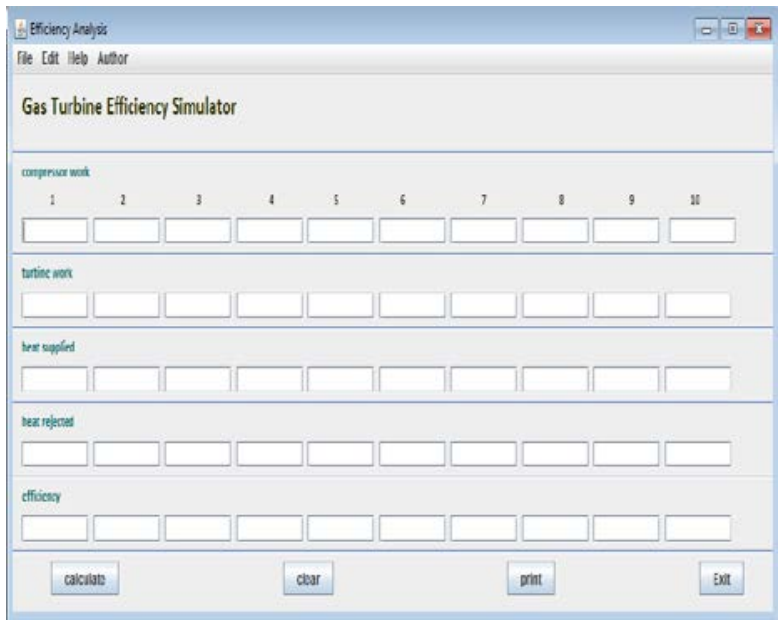

Figure 8. GT efficiency analysis interfacce of the computer mode

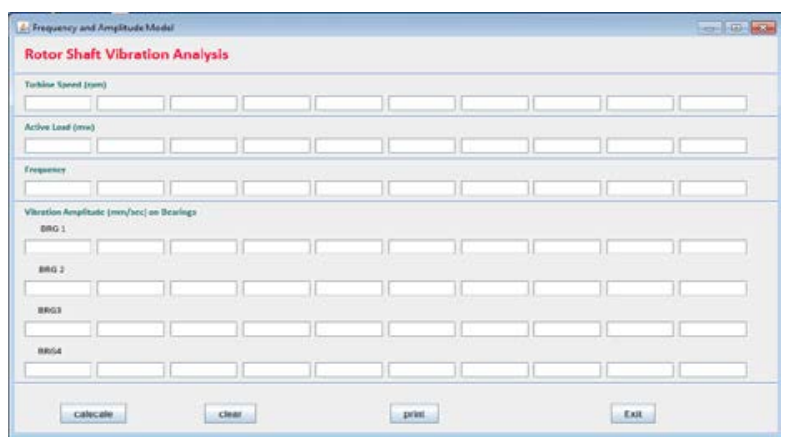

Figure 9. Program to calculate frequency and amplitude

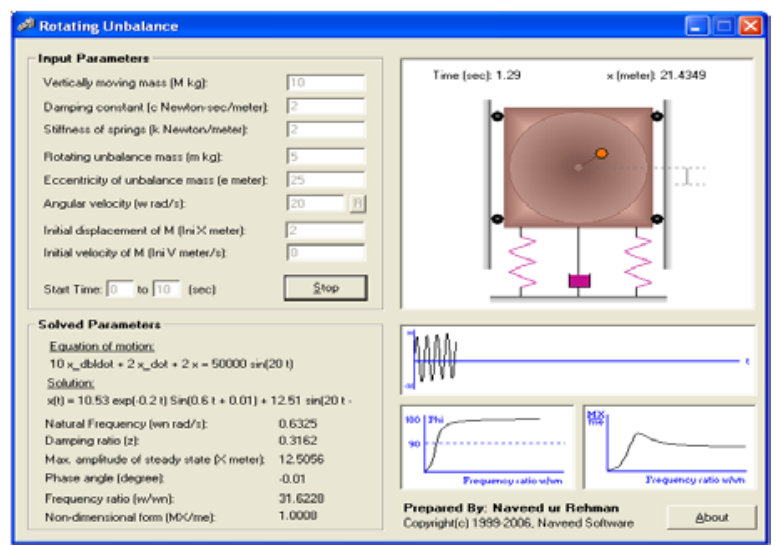

Figure 10. Computer model used for rotating unbalance analysis 


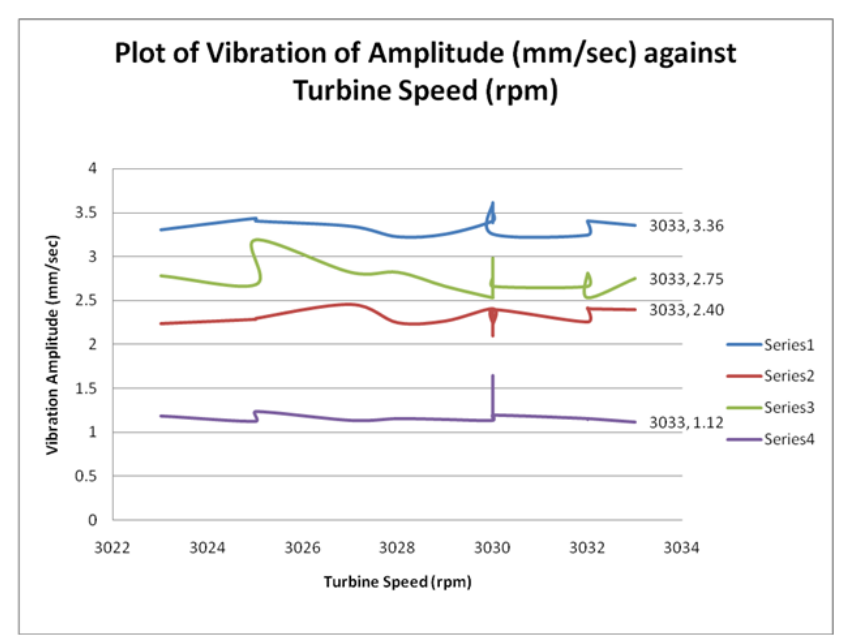

Figure 11. Vibration amplitude against turbine speed

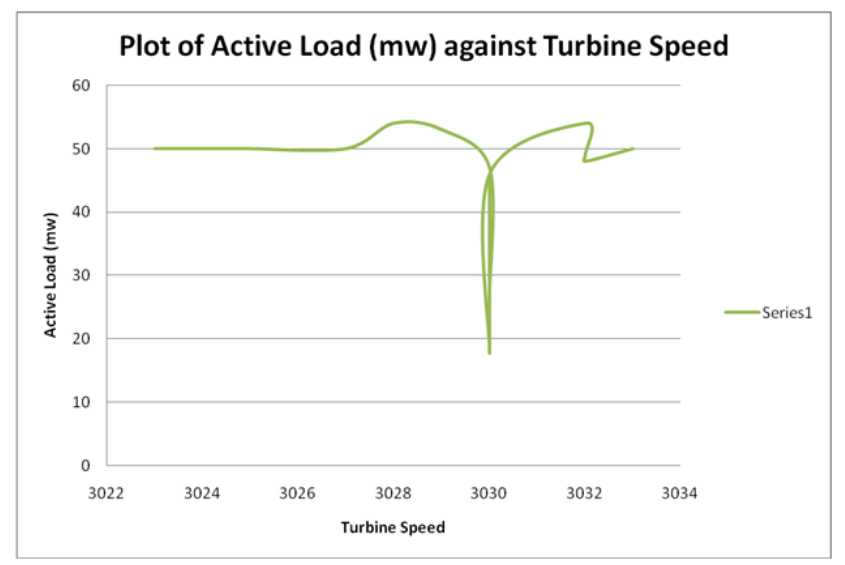

Figure 12. Active load against turbine speed

\subsection{Validation of Models}

The models developed in this paper were validated and seen as bearing superior to those earlier enunciated by the previous researchers. The earlier models either concentrated totally on looking at condition monitoring from the thermodynamics perspective (Aretaks, 2001), Theophilus-Johnson, et al (2012) or from one form of vibration monitoring or the other (Ogbonnaya et al, (2004)), Ugwu and Ogbonnaya (2011), Ogbonnaya and Theophilus-Johnson (2011), Simon and Armstrong (2012) to mention but a few.

There are a number of other works looked at in the course of this project where only the rotor shaft were treated towards the condition monitoring of the GT plant without considering the thermodynamic aspects. More so some of these did not have any computerized consideration (Shablinsky et al (2000)), Maynard et al (2001) and Azovksev and Barkov (2002).

From the paragraphs above, it is noticeable that the peculiarity with this present work is that it combines thermodynamics with rotalpy (rotor dynamics analysis) to proffer solution to gas turbine condition monitoring (Ogbonnaya, 2004b).

\section{Conclusion}

This study underscored an in-depth analysis of a marine GT proactive condition monitoring through rotor shaft vibration analysis. Critical analyses were performed using highly sophisticated, yet easy to use computer programs to simulate the various analyses required.

The following conclusions were drawn after considerable examinations of the subject matter: Proactive maintenance is the single most important means of achieving unsurpassed savings by conventional maintenance techniques. If well-developed, it could prevent equipment breakdown and downtime. It is also clear that vibration reduces the energy that could have been useful to wasteful energy. Rotating components of GT suffer the most from vibration which affects the plant in many ways causing misalignment.

\section{References}

[1] Aretaks, N (2001), "Contribution to Development of Gas Turbine Diagnostic Systems Using Fast Response Measurements Analysis Methods", PhD Thesis, National Technical University of Athens, Greece.

Available: http://www.ltt.mech.ntua.gr/naret/phdthesis.htm

[2] Azovksev, A and Barkov, A (2002), "Development of Condition Monitoring in Russia Using Vibration”, VAST Inc., St. Petersburg, Russia, pp.1-14.

Available: http://www.vibrotek.com/articles/russia/index.htm

[3] Bertele, V. (2002), "Why Condition Monitor?" 3rd International Conference on Condition Monitoring. October 15-16, 2002.

[4] Çengel, Y.A and Boles M.A (1998), "Thermodynamics: An Engineering Approach, McGraw -Hill, pp. 508-520. (ISBN: 0-07011927-9)

[5] Chaplin, J., "Improving Vehicle Productivity through Better Contamination Control." SAE Paper No. 861300. September, 2006.

[6] Denton, R and Ritmiller R (2011), "The Future of Vibration Sensor and Asset Marine Gas Turbine Beyond Sensor: Where Do We Go From Here? Wilcoxon Research, Inc., USA, pp. 1-3. Available: http://www.coxmoor.com/denton.html .

[7] Dodd, R.V. (2000), "Condition Monitoring of Major Turbomachinery Cuts Costs Over 4-year Period", Oil and Gas Journal.

[Available: www.acw.sdp.sirsi.net/client/search/asset/1002267]

[8] Katsuhiko, O. (2005), "System Dynamics" (4th Ed.). University of Minnesota, Pearson Pnmticc. Hidi, NJ. p.617. Available: www.amazon.com

[9] Maynard, K., Trethewey, M., Gill, R and Resor, B (2001), “Gas Turbine Blade and Disk Crack Detection Using Torsional Vibration Monitoring: A Feasibility Study", Proceeding of $14^{\text {th }}$ International Congress and Exhibition on Condition Monitoring (COMADEN), University of Manchester, U.K.

[10] Maynard, K.P, Trethewey, M.W and Groover, C.L (2001); "Application of Torsional Vibration Measurement to Shaft Crack Monitoring in Power Plant", 55 $5^{\text {th }}$ Meeting of the Society for Machinery Failure Prevention Technology, Virginia Beach, VA, USA.

[11] Ogbonnaya, E.A. (2004a), "Modeling Vibration-Based Faults in Rotor Shaft of a Gas Turbine. PhD Thesis, Department of Marine Engineering, Rivers State University of Science and Technology, Port Harcourt, Nigeria.

[12] Ogbonnaya, E.A. (2004b), "Thermodynamics of Steam and Gas Turbines" $1^{\text {st }}$ edition Oru's Press Ltd, Page 71-73.

[13] Ogbonnaya E.A., Bob-Manuel K.D.H., Douglas I.E and Hart H.I. (2004), "Application of Artificial Neural Network to Gas Turbine Rotor Shafts Diagnoses", Journal of Science and Technology Research, Volume 3, Number 1 (ISSN: 1596-9649).

[14] Ogbonnaya, E.A and Theophilus-Johnson, K (2011), “Optimizing Gas Turbine Rotor Shaft Fault Detection, Identification and Analysis for Effective Condition Monitoring”, JETEAS 2(1): 1117 Scholarlink Research Institute Journals (ISSN: 2141-7016).

[15] Rao, J. (2001), "Determining Financial Benefits for Predictive Maintenance and Developing Management Support." PPM Technology. May/June, 2001.

[16] Shablinsky, A.G., Barkov A.V and Barkova M.A. (2000), "Rotor Balancing for Multi-Condition Machines”, Vibro-Acoustic 
Systems and Technologies (VAST) Inc., Saint Petersburg, Russia. Available: http://www.Vibrotek.com/articles/rbmcm/index.htm.

[17] Simon, D.L and Armstrong, J.B (2012), “An Integrated Approval for Aircraft Engine Performance Estimation and Fault Diagnostics”, Paper\#GT2012-69905, ASME-Turbo Expo, June 11-15, 2012, Bella Centre, Copenhagen-Denmark.

[18] Singh, S (2009), "Mechanical Vibrations and Noise Control", Romesh Chander Khanna for KHANNA Publishers, Delhi, India, pp.70-95 (ISBN: 81-7409-167-x).

[19] Theophilus-Johnson,K., Ukpaka, C.P., Uba, H.U and Ogbonnaya, E.A (2012), "Influence of Proper Condition Monitoring on Gas Turbine Combustion Efficiency”, NSE Technical Transaction, Vol.46, No.4, ISSN 11195363, October-December,2012.
[20] Tarbet, M.A., (2001): “Gas Turbine Vibration Monitoring Systems" Magelian Publishing (A Division of Woodward Communication), Inc., Ohio-U.S.A. [Online Series] Available: http://energy-tech, com/issues/html/we 0006-007.html [2002, Feb. 20].

[21] Ugwu, H.U and Ogbonnaya, E.A (2011), "Simulating Gas Turbine Bearing Failure Towards Effective Condition Monitoring”, NSE Technical Transaction, Vol. 46, No.3. ISSN 11195363, Jul.-Sep., 2011.

[22] Verdegan, B. M., Thibodeau L and Stephen L. F (2002), "Lubricating Oil Condition Monitoring Through Particle Size Analysis."SAE Paper No. 8818.

\section{APPENDIX A.}

GT Thermodynamic Analysis Using Temperature and Constant Pressure Ratio

\begin{tabular}{|c|c|c|c|c|c|c|c|c|}
\hline $\begin{array}{c}\mathrm{T} 1 \\
(\mathrm{~K})\end{array}$ & $\begin{array}{l}\mathrm{T} 2 \\
(\mathrm{~K})\end{array}$ & $\begin{array}{l}\text { T3 } \\
(\mathrm{K})\end{array}$ & $\begin{array}{c}\mathrm{T} 4 \\
(\mathrm{~K})\end{array}$ & $\begin{array}{c}\text { Compressor } \\
\text { Work } \\
(\mathrm{KJ} / \mathrm{Kg})\end{array}$ & $\begin{array}{l}\text { Turbine } \\
\text { Work } \\
(\mathrm{KJ} / \mathrm{Kg})\end{array}$ & $\begin{array}{l}\text { Heat Supplied } \\
\quad(\mathrm{KJ} / \mathrm{Kg})\end{array}$ & $\begin{array}{c}\text { Network } \\
\text { Done }(\mathrm{KJ} / \mathrm{Kg})\end{array}$ & $\begin{array}{l}\text { Thermal } \\
\text { Efficiency } \\
(\mathrm{KJ} / \mathrm{Kg})\end{array}$ \\
\hline 300 & 448.9524 & 1213 & 810.5536 & 149.69716 & 404.4586 & 767.86784 & 254.76144 & $35.4 \%$ \\
\hline 303 & 453.4419 & 1505 & 1005.675 & 151.19414 & 501.8221 & 1056.8159 & 350.62795 & $35.2 \%$ \\
\hline 305 & 456.4349 & 1510 & 1009.016 & 152.19212 & 503.4893 & 1058.8329 & 351.29716 & $33.2 \%$ \\
\hline 307 & 459.428 & 1511 & 1009.684 & 153.1901 & 503.8227 & 1056.8299 & 350.63261 & $33.2 \%$ \\
\hline 309 & 462.421 & 1513 & 1011.02 & 154.18808 & 504.4896 & 1055.8319 & 350.3015 & $33.2 \%$ \\
\hline 311 & 465.414 & 1515 & 1012.357 & 155.18606 & 505.1565 & 1054.8339 & 349.9704 & $33.2 \%$ \\
\hline 313 & 468.407 & 1519 & 1015.03 & 156.18404 & 506.4902 & 1055.846 & 350.30616 & $33.2 \%$ \\
\hline 315 & 471.4 & 1522 & 1017.034 & 157.18202 & 507.4905 & 1055.853 & 350.30849 & $33.2 \%$ \\
\hline 317 & 474.393 & 1525 & 1019.039 & 158.18 & 508.4908 & 1055.86 & 350.31082 & $33.2 \%$ \\
\hline 319 & 477.3861 & 1529 & 1021.712 & 159.17799 & 509.8246 & 1056.872 & 350.64658 & $33.2 \%$ \\
\hline
\end{tabular}

APPENDIX B.

Generated Vibration Results

\begin{tabular}{|c|c|c|c|c|c|c|}
\hline \multirow{2}{*}{$\begin{array}{l}\text { Turbine } \\
\text { Speed } \\
\text { (RPM) }\end{array}$} & \multirow{2}{*}{$\begin{array}{c}\text { Active } \\
\text { Load(MW) }\end{array}$} & \multirow{2}{*}{ Frequency (Hz) } & \multicolumn{4}{|c|}{ Vibration Amplitude (mm) on Bearings } \\
\hline & & & BRG 1 & BRG 2 & BRG 3 & BRG 4 \\
\hline 3023 & 28 & 50.38 & 3.31 & 2.24 & 2.78 & 1.19 \\
\hline 3025 & 50 & 50.42 & 3.44 & 2.29 & 2.68 & 1.13 \\
\hline 3025 & 50 & 50.42 & 3.41 & 2.30 & 3.19 & 1.24 \\
\hline 3027 & 50 & 50.45 & 3.35 & 2.46 & 2.82 & 1.14 \\
\hline 3028 & 54 & 50.47 & 3.23 & 2.25 & 2.82 & 1.16 \\
\hline 3029 & 53 & 50.48 & 3.26 & 2.27 & 2.66 & 1.15 \\
\hline 3030 & 47 & 50.50 & 3.41 & 2.41 & 2.53 & 1.14 \\
\hline 3030 & 28 & 50.50 & 3.50 & 2.23 & 2.54 & 1.20 \\
\hline 3030 & 34 & 50.50 & 3.39 & 2.27 & 2.76 & 1.16 \\
\hline 3030 & 46 & 50.50 & 3.49 & 2.31 & 2.98 & 1.19 \\
\hline 3030 & 30 & 50.50 & 3.48 & 2.10 & 2.65 & 1.65 \\
\hline 3030 & 11 & 50.50 & 3.54 & 2.39 & 2.72 & 1.20 \\
\hline 3030 & 18 & 50.50 & 3.61 & 2.25 & 2.76 & 1.17 \\
\hline 3030 & 46 & 50.50 & 3.26 & 2.40 & 2.66 & 1.20 \\
\hline 3032 & 54 & 50.53 & 3.25 & 2.26 & 2.66 & 1.16 \\
\hline 3032 & 49 & 50.53 & 3.40 & 2.42 & 2.81 & 1.15 \\
\hline 3032 & 48 & 50.53 & 3.41 & 2.41 & 2.53 & 1.16 \\
\hline 3033 & 50 & 50.55 & 3.36 & 2.40 & 2.75 & 1.12 \\
\hline
\end{tabular}

